\title{
The global palm oil sector must change to save biodiversity and improve food security in the tropics
}

\begin{abstract}
Most palm oil currently available in global markets is sourced from certified large-scale plantations. Comparatively little is sourced from (typically uncertified) smallholders. We argue that sourcing sustainable palm oil should not be determined by commercial certification alone and that the certification process should be revisited. There are so-far unrecognized benefits of sourcing palm oil from smallholders that should be considered if genuine biodiversity conservation is to be a foundation of 'environmentally sustainable' palm oil production. Despite a lack of certification, smallholder production is often more biodiversityfriendly than certified production from large-scale plantations. Sourcing palm oil from smallholders also alleviates poverty among rural farmers, promoting better conservation outcomes. Yet, certification schemes - the current measure of 'sustainability' - are financially accessible only for large-scale plantations that operate as profit-driven monocultures. Industrial palm oil is expanding rapidly in regions with weak environmental laws and enforcement. This warrants the development of an alternative certification scheme for smallholders. Greater attention should be directed to deforestation-free palm oil production in smallholdings, where production is less likely to cause large scale biodiversity loss. These small-scale farmlands in which palm oil is mixed with other crops should be considered by retailers and consumers who are interested in promoting sustainable palm oil production. Simultaneously, plantation companies should be required to make their existing production landscapes more compatible with enhanced biodiversity conservation.
\end{abstract}

Keyword: Biodiversity; Certification; Conservation; Plantation; Poverty; Smallholding 